Check for updates

Cite this: RSC Adv., 2017, 7, 33020

Received 14th May 2017

Accepted 23rd June 2017

DOI: $10.1039 / \mathrm{c} 7 \mathrm{ra0} 438 \mathrm{f}$

rsc.li/rsc-advances

\section{The preparation of fluorine-containing polysiloxane low-melting glass and its effect on the tracking resistance and thermostability of addition- cure liquid silicone rubber}

\begin{abstract}
Fengjiao Liu, Xingrong Zeng, (D)* Xuejun Lai and Hongqiang Li
Fluorine-containing polysiloxane low-melting glass (FPLMG) was prepared by the hydrolysis-condensation of tridecafluorooctyltriethoxysilane (FAS), vinyltriethoxysilane (ViTES) and phenyltriethoxysilane (PhTES). FPLMG was characterized by Fourier transform infrared spectrometry (FTIR), nuclear magnetic resonance spectrometry $\left({ }^{1} \mathrm{H}\right.$-NMR), X-ray diffraction (XRD), gel permeation chromatography (GPC), differential scanning calorimetry (DSC) and thermogravimetric analysis (TG). The effect of FPLMG with different FAS content on the mechanical and hydrophobic properties, tracking resistance and thermal stability of addition-cure liquid silicone rubber (ALSR) was investigated. The results showed that FPLMG had an amorphous ladder-like structure. The molecular weight and glass transition temperature of FPLMG increased with more addition of FAS. The tracking resistance and hydrophobicity of ALSR could be significantly enhanced by FPLMG. FPLMG formed a "glassy layer" on the surface of ALSR, which effectively improved the thermal stability of silicone rubber. Therefore, the tracking resistance of ALSR was enhanced because of the improvement of hydrophobicity and thermal stability of ALSR by FPLMG.
\end{abstract}

\section{Introduction}

Silicone rubber has excellent high and low temperature resistance, electrical insulation property, hydrophobicity and hydrophobicity recovery and so on. It is gradually replacing the traditional insulating materials, such as glass and porcelain, in high voltage transmission areas. ${ }^{1-6}$ However, the hydrophobicity of silicone rubber might be reduced or even lost owing to its exposure to elevated voltage level and environmental deterioration during long-term operation. The loss of surface hydrophobicity accelerated the deposition of contaminants in heavy wet weather. Once under the applied electric field, local electric field distribution would be altered by contaminants, which resulted in the formation of leakage current. The water on the surface of silicone rubber would evaporate under the influence of current joule heat, and then dry-band discharge was formed. These electrical discharges would lead to the concentration of a mass of heat, and then causing the thermal degradation of the silicone rubber. Consequently, the silicone rubber undergoes electrical tracking, destabilizing its electrical insulation property. $^{7-10}$

Nowadays, the common method to improve the tracking resistance of silicone rubber is the incorporation of inorganic

College of Materials Science and Engineering, South China University of Technology, No 381, Wushan Road, Tianhe District, Guangzhou 510640, People's Republic of China. E-mail: psxrzeng@gmail.com; Fax: +86 208711 4248; Tel: +86 2087114248 anti-tracking additives, such as alumina trihydrate (ATH). ${ }^{\mathbf{1 1 - 1 3}}$ However, high polarity of inorganic additives, poor compatibility between inorganic additives and silicone rubber, and heavy load for the desired tracking resistance would severely deteriorate the mechanical and hydrophobic properties of silicone rubber. Thus, it is extremely urgent to study one novel and efficient organic anti-tracking additive with excellent compatibility with silicone rubber. The frequently-used organic antitracking additives in our research group are the urea- or amino-containing siloxane, ${ }^{\mathbf{1 4}, 15}$ of which high polarity might reduce the hydrophobicity of silicone rubber. Therefore, it is of meaningfully significance for the application and development of silicone rubber to not only improve its tracking resistance but also retain its hydrophobic and mechanical properties.

Fluorinated modification can improve the hydrophobicity of silicone rubber because fluorine atoms have lower surface energy than silicone atoms. ${ }^{16-23}$ Besides, Du et al. found that fluorination could also dissipate the surface charge of room temperature vulcanized silicone rubber. The reason was that fluorine element had high electric negativity, which made the $\mathrm{C}-\mathrm{F}$ bond highly polarized. The fluorinated layer would capture electrons once under the applied electric field. An inverse field was formed in the vicinity of anode, weakening the effective field between the electrode and sample. ${ }^{24}$ Therefore, introducing the fluorine element into silicone rubber might improve its hydrophobicity and tracking resistance. 
In recent years, organic-inorganic hybrid low-melting glass also develops a new route for the anti-tracking additives of silicone rubber. Organic-inorganic hybrid low-melting glass, a novel organic-inorganic hybrid materials, is in transparent glassy state at room temperature, and can transform into fluid liquid at relative low temperature. ${ }^{25}$ It has applicable prospects in the improvement of the flame retardance, high temperature resistance, tracking and erosion resistance and other properties of polymer. ${ }^{26,27} \mathrm{Yu}$ et al. introduced polysiloxane low-melting glass into epoxy composites, and found that polysiloxane lowmelting glass would form a glassy protective layer when heated and significantly enhanced the ablative resistance and surface barrier properties of epoxy. ${ }^{26}$ Therefore, organically combining fluorine element and organic-inorganic low-melting glass would not only improve the hydrophobicity of silicone rubber and dissipate its surface charge, but also effectively barrier the transmission of heat and flammable gas by forming the "glassy layer" at high temperature. It might be favorable to enhance the tracking resistance property of silicone rubber and broaden its application. However, there were few reports about the incorporation of fluorine element into organic-inorganic hybrid low-melting glass and the application of organic-inorganic hybrid low-melting glass in silicone rubber.

In this work, fluorine-containing polysiloxane low-melting glass (FPLMG) was prepared by hydrolysis-condensation of tridecafluorooctyltriethoxysilane (FAS), vinyltriethoxysilane (ViTES) and phenyltriethoxysilane (PhTES) via one-step hydrochloric acid catalyzed sol-gel method. FPLMG was characterized by Fourier transform infrared spectrometry (FTIR), nuclear magnetic resonance spectrometry $\left({ }^{1} \mathrm{H}-\mathrm{NMR}\right), \mathrm{X}$-ray diffraction (XRD), gel permeation chromatography (GPC), differential scanning calorimetry (DSC) and thermogravimetric analysis (TGA). The effect of FPLMG with different FAS content on the tracking resistance, mechanical property, hydrophobicity and thermal stability of addition-cure liquid silicone rubber (ALSR) was investigated.

\section{Experimental}

\subsection{Materials}

Tridecafluorooctyltriethoxysilane (FAS) was obtained from Evonik Industries Group, Germany. Phenyltriethoxysilane (PhTES) was purchased from Hubei Jianghan Fine Chemical Co., Ltd., China. Vinyltriethoxysilane (ViTES) was supplied by Qufu Chenguang Chemical Co., Ltd., China. Toluene and hydrochloric acid were obtained from Guangzhou Chemical Reagent Factory, China. Ethanol was purchased from Tianjin Fuyu Fine Chemical Co., Ltd., China. Vinyl-terminated poly(dimethylsiloxanes) (VPDMS, viscosity was $24320 \mathrm{mPa}$ s and vinyl content was $0.28 \mathrm{wt} \%$ ) was obtained from Midgold Fine Performance Materials Co., Ltd., China. Poly(hydromethylsiloxane) (PHMS, vinyl content was $0.75 \mathrm{wt} \%$ ) was purchased from Shandong Dayi Chemical Co., Ltd., China. 1Ethynylcyclohexanol, Karstedt's catalyst (platinum content was $2000 \mathrm{ppm}$ ) and poly(dimethylsiloxanes) with high vinyl content (viscosity was $2095 \mathrm{mPa}$ s and vinyl content was $8.7 \mathrm{wt} \%$ ) were supplied by Guangzhou Tinci Silicon Technology Co., Ltd.,
China. Fumed silica $\left(\mathrm{SiO}_{2}\right.$, QS-25, specific surface area was 250 $\mathrm{m}^{2} \mathrm{~g}^{-1}$ ) was obtained from Tokuyama Corp, Japan. Hexamethyldisilazane (HMDS) was purchased from Jilin Xinya Qiangshengwu Chemical Co., Ltd., China. Distilled water was prepared by our laboratory.

\subsection{Preparation of fluorine-containing polysiloxane low- melting glass}

Fluorine-containing polysiloxane low-melting glass (FPLMG) was prepared by one-step hydrochloric acid catalyzed sol-gel method. A certain amount of tridecafluorooctyltriethoxysilane (FAS) (shown as Table 1), $0.12 \mathrm{~mol}$ vinyltriethoxysilane (ViTES) and $0.88 \mathrm{~mol}$ phenyltriethoxysilane (PhTES) diluted with $4.3 \mathrm{~mol}$ ethanol in $150 \mathrm{~mL}$ constant pressure funnel were added dropwise to a mixture of $5.7 \mathrm{~mol}$ ethanol, $3 \mathrm{~mol} \mathrm{H}_{2} \mathrm{O}$ and $0.1 \mathrm{~mol}$ $\mathrm{HCl}$ in $250 \mathrm{~mL}$ four-neck flask with reflux apparatus under stirring at $30{ }^{\circ} \mathrm{C}$. Then the mixture was heated up to $60{ }^{\circ} \mathrm{C}$ and reacted for $3 \mathrm{~h}$. To increase the reaction degree, the mixture was further heated up to $150{ }^{\circ} \mathrm{C}$ and kept for $24 \mathrm{~h}$. The ethanol was removed by rotary evaporation under reduced pressure, and then fluorine-containing polysiloxane low-melting glass (FPLMG) was obtained. The synthetic diagram of FPLMG is shown in Fig. 1.

\subsection{Preparation of ALSR samples}

100 phr VPDMS, 6.8 phr HMDS, 40 phr $\mathrm{SiO}_{2}$ and 2 phr poly(dimethylsiloxanes) with high vinyl content were mixed uniformly in stirring kneader, and then 1.9 phr PHMS, 0.06 phr 1-ethynylcyclohexanol, 3 phr FPLMG and 15 ppm Karstedt's catalyst were sequentially added to the mixture. Afterwards the mixture was vulcanized for $10 \mathrm{~min}$ at $120{ }^{\circ} \mathrm{C}$, and then vulcanized again for $1 \mathrm{~h}$ at $150{ }^{\circ} \mathrm{C}$. The codes of ALSR samples are listed in Table 2 according to the different kinds of FPLMG added into silicone rubber.

\subsection{Characterization}

2.4.1 Fourier transform infrared spectrometry (FTIR). Fourier transform infrared spectrometry (FTIR) was taken with FTIR spectroscope (Bruker Optics, TENSOR-27, Germany). FPLMG samples were dissolved into toluene, and painted on the $\mathrm{KBr}$ slice. The toluene was removed by drying treatment. The transmittance spectra were recorded in the range of 4000 $\mathrm{cm}^{-1}$ to $400 \mathrm{~cm}^{-1}$ with 16 scans and resolution of $4.0 \mathrm{~cm}^{-1}$.

2.4.2 ${ }^{1} \mathrm{H}$ nuclear magnetic resonance spectrometry $\left({ }^{1} \mathrm{H}\right.$ NMR). ${ }^{1} \mathrm{H}$-NMR spectrometry was performed with NMR spectroscope (Bruker, AVANCE III HD 600, Germany), and operated at $25{ }^{\circ} \mathrm{C}$. 5-10 $\mathrm{mg}$ dried sample was dissolved into $6 \mathrm{~mL}$ deuterated chloroform, and tetramethylsilane was taken as the internal standard.

2.4.3 X-ray diffraction (XRD). The X-ray diffraction (XRD) was performed using source of $\mathrm{CuK} \alpha$ radiation by $\mathrm{X}$-ray diffractometer (Bruker, D8 ADVANCE X, Germany), operating at $40 \mathrm{kV}$ and $40 \mathrm{~mA} \mathrm{X}$-ray beam. The bulk sample was grinded into powder for test, and the X-ray diffraction spectra were recorded in the $2 \theta$ range from $5^{\circ}$ to $80^{\circ}$. 
Table 1 The content of FAS for the preparation of FPLMG

\begin{tabular}{lllllll}
\hline Samples & FPLMG0 & FPLMG1 & FPLMG2 & FPLMG3 & FPLMG4 \\
\hline $\mathrm{M}_{\mathrm{FAS}} / \mathrm{mol} \%$ & - & 1.70 & 3.90 & 5.70 & 7.40 & 10.7
\end{tabular}

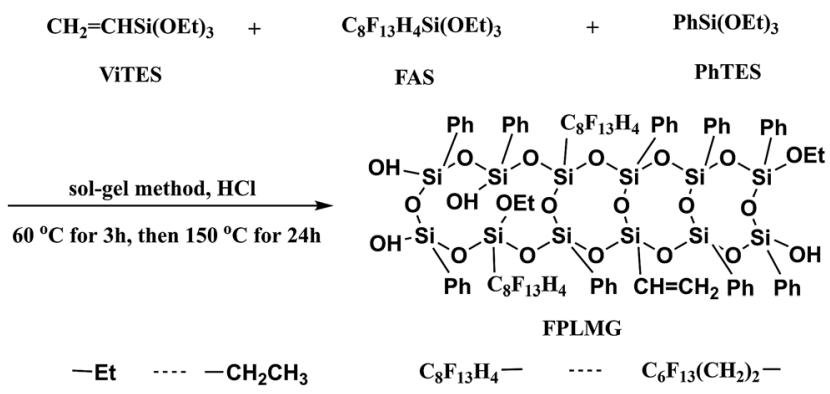

Fig. 1 Synthetic diagram of FPLMG.

2.4.4 Gel permeation chromatograph (GPC). Gel permeation chromatography (GPC) was performed using a Waters 515 HPLC pump (Waters, USA) equipped with a Shodex K-G guard column and a Shodex K-804L chromatographic column. Detection was achieved using a Waters 2414 refraction index detector, and the sample was analyzed at $30{ }^{\circ} \mathrm{C}$ using chloroform as the eluent at a flow rate of $1 \mathrm{~mL} \mathrm{~min}^{-1}$. The instrument was calibrated using narrow polydispersity polystyrene standards.

2.4.5 Differential scanning calorimetry (DSC). Glass transition temperature $\left(T_{\mathrm{g}}\right)$ was measured with differential scanning calorimetry (DSC) using a differential scanning calorimetry instruments (Netzsch, DSC204F1, Germany). To eliminate heat history, double scanning method was adopted, where sample with a weight of 3 to $5 \mathrm{mg}$ in an aluminum crucible was tested at a heating rate of $20 \mathrm{~K} \mathrm{~min}^{-1}$ in the range of -30 to $250{ }^{\circ} \mathrm{C}$, and then at a cooling rate of $10 \mathrm{~K} \mathrm{~min}^{-1}$ in the range of 250 to $-30{ }^{\circ} \mathrm{C}$, and finally at the heating rate of $20 \mathrm{~K} \mathrm{~min}^{-1}$ in the range of -30 to $250{ }^{\circ} \mathrm{C}$ in nitrogen atmosphere.

2.4.6 Thermogravimetric analysis (TGA). Thermogravimetric analysis (TGA) was conducted using a thermogravimetric analyzer (Netzsch Instruments, TG209, Germany) from $30{ }^{\circ} \mathrm{C}$ to $800^{\circ} \mathrm{C}$ at the heating rate of $20 \mathrm{~K} \mathrm{~min}^{-1}$ in air atmosphere. Each sample measured in an alumina crucible was weighed in the range of 5 to $10 \mathrm{mg}$.

2.4.7 Mechanical property test. The tensile and tear properties of ALSR samples were tested using tensile testing machine (Taiwan Youken Science and Technology Co., Ltd., UT2060DE, China) according to the ISO 37-2005 and ISO 34-12004, respectively. In accordance with ISO 7619-1-2004, the Shore A hardness was conducted with the Shore A durometer (Shanghai Liuling Instruments Factory, LX-A, China).
2.4.8 Incline plane test (IP test). The tracking resistance of ALSR samples was measured with an inclined plane tracking and erosion resistance test apparatus (Dongguan Daxian Mechanical Co., Ltd., DX8427, China) via incline plane test (IP test) according to IEC 60587 standard. Five specimens with the dimensions of $120 \times 50 \times 60 \mathrm{~mm}^{3}$, as parallel specimens, were installed in an inclination of $45^{\circ}$. The constant voltage applied on ALSR was $4.5 \mathrm{kV}$ ac. During the whole process, the standard conductive solution $(0.1 \mathrm{wt} \%$ ammonium chloride and $0.2 \mathrm{wt} \%$ isooctylphenoxypolyethoxyethanol, with conductivity of $3.95 \Omega$ $\mathrm{m}$ ) was continuously flowing at the rate of $0.6 \mathrm{~mL} \mathrm{~min}^{-1}$ on the surface of ALSR samples. When the tracking length reached up to $25 \mathrm{~mm}$ away from the bottom electrodes, the apparatus would record this moment as the time to failure. The IP test was discontinued when tracking time was up to $6 \mathrm{~h}$, and then the testing time of every specimen was recorded. The schematic diagrams of IP test and sample setup are showed in Fig. 2.

2.4.9 Static contact angle. The static contact angle of ALSR samples was conducted at room temperature with an contact angle meter (KRUSS, DSA100, Germany) according to GB/T 30693-2014 standard. A drop of water of $5 \mu \mathrm{L}$ was carefully dripped on the horizontally laid specimen cleaned with deionized water. Five different points of each specimen were required to be tested and the average contact angle was calculated.

2.4.10 High temperature heat treatment of ALSR samples. The high temperature heat treatment of ALSR samples was

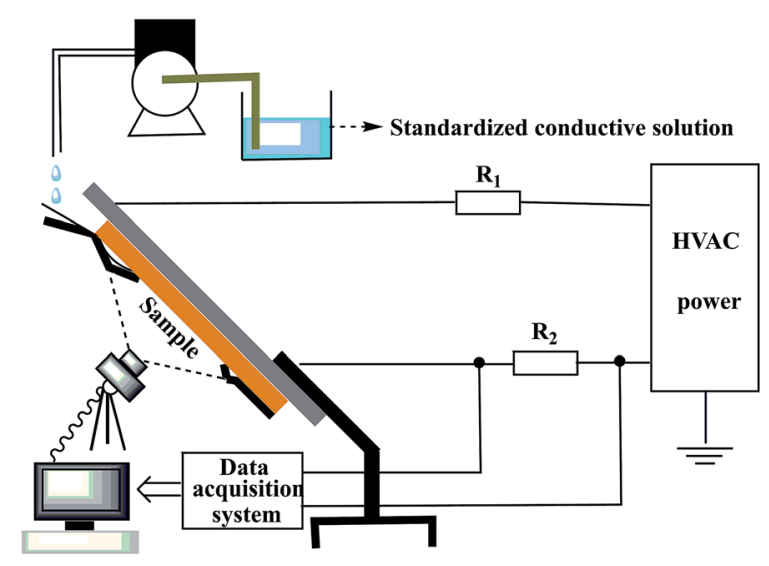

Fig. 2 Inclined plane test setup for AC tracking and erosion resistance test.

Table 2 The codes of ALSR samples

\begin{tabular}{lllllllll}
\hline Samples & N-SR & FS-0 & FS-1 & FS-2 & FS-3 & FS-4 & FS-5 \\
\hline Kind of FPLMG & - & FPLMG0 & FPLMG1 & FPLMG2 & FPLMG3 & FPLMG4
\end{tabular}


measured with the muffle furnace (Nabertherm, LT15/12/P330, Germany). The ALSR samples with the dimensions of $1 \times 1 \times 2$ $\mathrm{cm}^{3}$ were placed on the lid of crucible, and treated for $10 \mathrm{~min}$ at $800{ }^{\circ} \mathrm{C}$.

2.4.11 Thermogravimetry-Fourier transform infrared spectrometry (TG-FTIR). The TG-FTIR instrument consists of a TG analyser (Netzsch, STA-449C, Germany), an FTIR spectrometer (Bruker, TENSOR-27, Germany), and a transfer tube connecting these two parts. The samples of 15-20 mg was treated from 30 to $900{ }^{\circ} \mathrm{C}$ at the heat rate of $20 \mathrm{~K} \mathrm{~min}^{-1}$. The temperature of transfer tuber was set to $230^{\circ} \mathrm{C}$. The transmittance spectra were recorded in the range of $4000 \mathrm{~cm}^{-1}$ to $400 \mathrm{~cm}^{-1}$ with resolution of $4.0 \mathrm{~cm}^{-1}$.

\section{Results and discussion}

\subsection{Characterization of FPLMG}

3.1.1 FTIR. The FTIR spectra of FAS, PhTES, ViTES, FPLMG0 and FPLMG3 are showed in Fig. 3. For FAS as shown in Fig. 3(a), the peak located at $1243 \mathrm{~cm}^{-1}$ was assigned to the stretching vibration of $\mathrm{C}-\mathrm{F}$ linkage. ${ }^{28}$ The bands at $956 \mathrm{~cm}^{-1}$ and $1084 \mathrm{~cm}^{-1}$ were attributed to the symmetrical and asymmetrical stretching vibration of $\mathrm{Si}-\mathrm{O}-\mathrm{C}$, respectively. The peaks at 2840-3000 $\mathrm{cm}^{-1}$ corresponded to the stretching vibration of the $\mathrm{C}-\mathrm{H}$ of $-\mathrm{CH}_{2} \mathrm{CH}_{3}$. For PhTES in Fig. 3(b), the bands located at $3040-3080 \mathrm{~cm}^{-1}, 1597 \mathrm{~cm}^{-1}, 1433 \mathrm{~cm}^{-1}, 742 \mathrm{~cm}^{-1}$ and 696 $\mathrm{cm}^{-1}$ belonged to the characteristic vibrations of $\mathrm{C}-\mathrm{H}$ of $\mathrm{Si}-$ $\mathrm{C}_{6} \mathrm{H}_{5} \cdot{ }^{26}$ In Fig. 3(c), the peak at $1010 \mathrm{~cm}^{-1}$ was attributed to the out-of-plane bending vibration of $\mathrm{C}-\mathrm{H}$ of $\mathrm{CH}=\mathrm{CH}_{2}$ in ViTES. ${ }^{29}$ For FPLMG0 in Fig. 3(d), there was distinct peak separation at $1050 \mathrm{~cm}^{-1}$ and $1150 \mathrm{~cm}^{-1}$ after the reaction of PhTES and ViTES, which were assigned to the symmetrical and asymmetrical stretching vibration of $\mathrm{Si}-\mathrm{O}-\mathrm{Si}$, respectively. ${ }^{30}$ The distinctly characteristic peak of $-\mathrm{CH}=\mathrm{CH}_{2}$ did not appear owing to the low content of vinyl groups and the overlap peaks of $\mathrm{Si}-\mathrm{O}-\mathrm{Si}$ at $1000-1150 \mathrm{~cm}^{-1}$ and $\mathrm{C}-\mathrm{H}$ of $-\mathrm{CH}=\mathrm{CH}_{2}$ at 1010 $\mathrm{cm}^{-1}$. The bands located at $742 \mathrm{~cm}^{-1}$ and $696 \mathrm{~cm}^{-1}$ attributed to the out-of-plane bending vibration of $\mathrm{C}-\mathrm{H}$ of $\mathrm{Si}-\mathrm{C}_{6} \mathrm{H}_{5}$ appeared, which demonstrated that ViTES and PhTES were successfully condensed. There were characteristic peaks of $-\mathrm{OCH}_{2} \mathrm{CH}_{3}$ and $-\mathrm{OH}$ at $2840-3000 \mathrm{~cm}^{-1}$ and $3320-3400 \mathrm{~cm}^{-1}$,

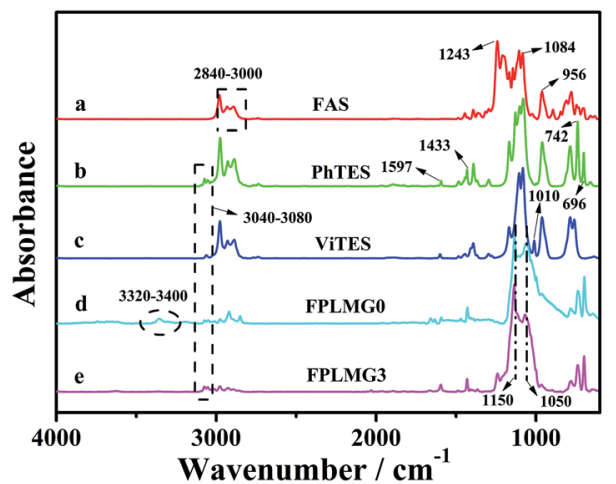

Fig. 3 FTIR spectra of FAS (a), PhTES (b), ViTES (c), FPLMGO (d) and FPLMG3 (e). respectively, indicating that ethyoxyl and hydroxy groups still existed in PhLMG0. For FPLMG3 in Fig. 3(e), after FAS, PhTES and ViTES were reacted, the band at $1243 \mathrm{~cm}^{-1}$ attributed to the stretching vibration of $\mathrm{C}-\mathrm{F}$ appeared, and other characteristic peaks were similar to those of FPLMG0, which manifested that fluorine-containing polysiloxane low-melting glass was successfully prepared.

3.1.2 ${ }^{1}$ H-NMR. Fig. 4 shows the ${ }^{1} \mathrm{H}$-NMR spectra of FPLMG with different FAS content. For FPLMG0 in Fig. 4(a), the characteristic signals located at 6.5-7.8 ppm and 5.6-6.3 ppm were attributed to the protons of $-\mathrm{C}_{6} \underline{\mathrm{H}}_{5}$ and $-\mathrm{OH}$, respectively. The signals of the protons of $-\mathrm{CH}=\mathrm{CH}_{2}$ and $-\mathrm{CH}=\mathrm{CH}_{2}$ were located at 5.2-5.4 ppm. The protons of $-\mathrm{CH}_{2} \mathrm{CH}_{3}$ and $-\mathrm{CH}_{2} \mathrm{CH}_{3}$ had the characteristic signals at 3.2-4.0 ppm and 0.5-1.5 ppm, respectively. It was demonstrated that PhTES and ViTES were successfully condensed, and there still existed ethyoxyl and hydroxy groups in FPLMG0. As shown in Fig. 4(b)-(f), after PhTES, ViTES and FAS were reacted, the characteristic signal at $1.5 \mathrm{ppm}$ of the protons of $-\mathrm{CF}_{2} \mathrm{CH}_{2} \mathrm{CH}_{2}$ - appeared, of which relative intensity intensified with the increase of FAS content. Other signals were similar to the ones as shown in Fig. 4(a). It was also indicated that fluorine-containing polysiloxane lowmelting glass was successfully obtained.

3.1.3 XRD. The XRD spectra of FPLMG with different FAS content are showed in Fig. 5. As shown in Fig. 5, there were two typical diffraction peaks with the spacing of $d_{2}=1.2 \mathrm{~nm}\left(2 \theta=7^{\circ}\right)$ and $d_{1}=0.5 \mathrm{~nm}\left(2 \theta=19^{\circ}\right)$, which were ascribed to the chain-tochain distance and intra-chain distance of ladder-like polysiloxane, respectively. ${ }^{31-34}$ The presence of $d_{2}$ manifested that FPLMG possessed amorphous ladder-like structure. Meanwhile, the ratio of peak area of corresponding peak of $d_{2}$ to that of $d_{1}$ (marked as $R$ ) could signify the structural regularity of ladderlike structure which demonstrated the proportion of ladderlike segments to total segments. And the value of $R$ descended with the decrease of structural regularity. ${ }^{35}$ As calculated in Fig. 5, the values of $R$ of FPLMG0, FPLMG1, FPLMG2, FPLMG3, FPLMG4 and FPLMG5 were 2.9, 2.7, 2.6, 2.5, 1.6 and 1.2, respectively, which demonstrated that the structural regularity of FPLMG decreased as FAS content increased. It might be because the hydrolysis-condensation of PhTES was still predominant in the system since the molar content of PhTES was much higher 


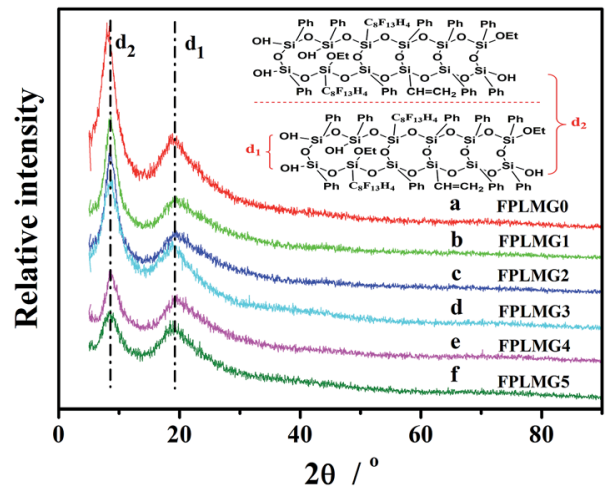

Fig. 5 XRD spectra of FPLMG with different FAS content.

than that of FAS. However, the inductive effect of tridecafluorooctyl group was prone to the condensation of hydroxy group when compared with phenyl group, and the segment activity of FAS was higher than that of PhTES owing to the lower steric hindrance of tridecafluorooctyl group. The ladder-like structure of final product without FAS would be arranged in a certain order. However, the ladder-like structure of final product might be destroyed by the addition of FAS.

3.1.4 GPC. The GPC curves of FPLMG with different FAS content are showed in Fig. 6. In Fig. 6, the molecular weight $\left(M_{\mathrm{n}}\right)$ of FPLMG and polydispersity index (PDI) both increased with more addition of FAS. The reason was that the reaction activity of FAS was higher than that of PhTES because of the inductive effect and lower steric hindrance of tridecafluorooctyl group. Moreover, the molecular weight of tridecafluorooctyl group was higher than that of phenyl group. Therefore, $M_{\mathrm{n}}$ of FPLMG increased with more addition of FAS.

3.1.5 DSC. Fig. 7 presents the DSC curves of FPLMG with different FAS content. In Fig. 7, the glass transition temperature $\left(T_{\mathrm{g}}\right)$ of FPLMG0 was $56^{\circ} \mathrm{C}$, which was basically similar to that of polysilsesquioxane low-melting glass prepared by Yu et $a l^{26}$ After the addition of FAS, $T_{\mathrm{g}}$ of FPLMG increased with more content of FAS. It was because the polarity of tridecafluorooctyl group was higher than that of phenyl group, and the molecular weight of FPLMG increased with more content of FAS, which contributed to the increase of $T_{\mathrm{g}}$.

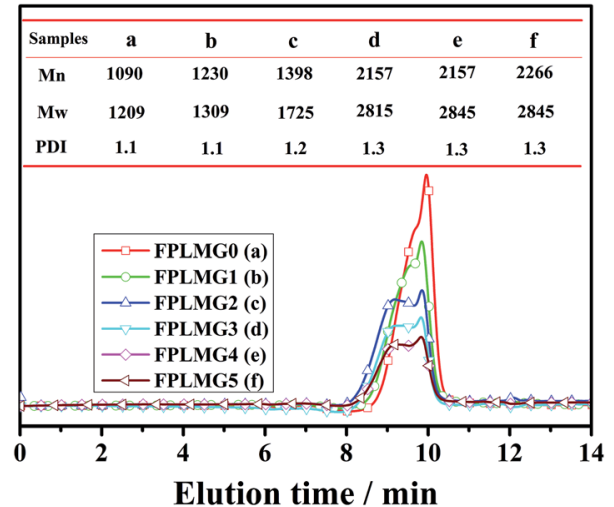

Fig. 6 GPC curves of FPLMG with different FAS content.

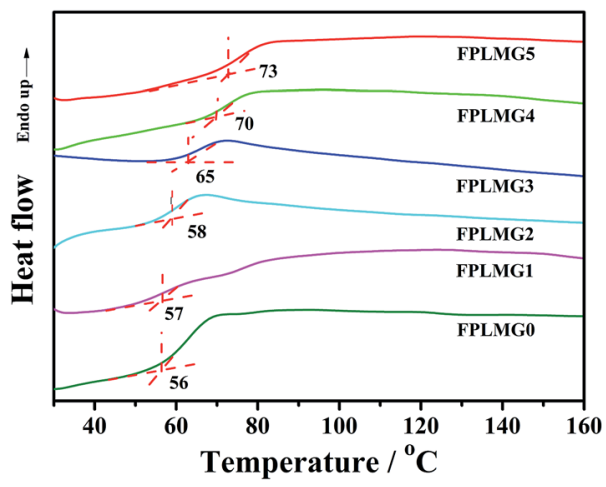

Fig. 7 DSC curves of FPLMG with different FAS content.

3.1.6 TG. The TG curves of FPLMG with different FAS content are showed in Fig. 8. As shown in Fig. 8, there were three main degradation stages of FPLMG0 in air atmosphere. The first degradation stage with $5.6 \%$ weight loss from $267^{\circ} \mathrm{C}$ to $398^{\circ} \mathrm{C}$ was ascribed to the further condensation of ethyoxyl and hydroxy groups. The second degradation stage from $402{ }^{\circ} \mathrm{C}$ to $602{ }^{\circ} \mathrm{C}$ was attributed to the oxidative degradation of side vinyl and phenyl groups. The third degradation stage from $610^{\circ} \mathrm{C}$ to $730{ }^{\circ} \mathrm{C}$ was caused by the thermal degradation of phenyl group and $\mathrm{Si}-\mathrm{O}-\mathrm{Si}$ backbone. Besides, the temperature of $5 \%$ weight loss $\left(T_{5}\right)$ of FPLMG0 was $379^{\circ} \mathrm{C}$, and residue at $900{ }^{\circ} \mathrm{C}\left(W_{900}\right)$ was $44.7 \mathrm{wt} \%$. The thermal degradation behavior of FPLMG with the addition of FAS was similar to that of FPLMG0. However, $T_{5}$ and $W_{900}$ of FPLMG were lowered with more content of FAS. It could be explained that tridecafluorooctyl group was easily subjected to the oxidation and bond scission of side groups in the form of $-\mathrm{Si}-\mathrm{CH}_{2}-\mathrm{CH}_{2}-\mathrm{C}_{6} \mathrm{~F}_{13}$. Therefore, the content of phenyl groups with good thermal stability decreased as FAS content increased, which resulted in the decrease of thermal stability of FPLMG.

\subsection{Effect of FPLMG on the mechanical properties of ALSR}

Table 3 presents the effect of FPLMG with different FAS content on the mechanical properties of ALSR. The mechanical properties of ALSR were obviously enhanced by FPLMG, especially for the tear strength of ALSR. The tear strength of ALSR with FPLMG was improved as FAS content increased. The tear

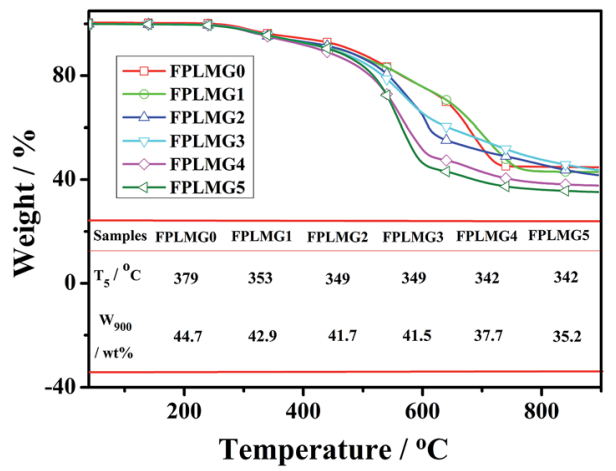

Fig. 8 TG curves of FPLMG with different FAS content (air, $20 \mathrm{~K} \mathrm{~min}^{-1}$ ). 
Table 3 Effect of FPLMG with different FAS content on the mechanical properties of the ALSR

\begin{tabular}{|c|c|c|c|c|c|c|c|}
\hline Samples & N-SR & FS-0 & FS-1 & FS-2 & FS-3 & FS-4 & FS-5 \\
\hline Tensile strength/MPa & $8.5 \pm 0.2$ & $8.6 \pm 0.1$ & $8.7 \pm 0.2$ & $8.8 \pm 0.1$ & $8.8 \pm 0.2$ & $9.1 \pm 0.3$ & $9.2 \pm 0.2$ \\
\hline Elongation at break/\% & $613 \pm 15$ & $620 \pm 18$ & $623 \pm 20$ & $632 \pm 24$ & $650 \pm 23$ & $651 \pm 15$ & $651 \pm 20$ \\
\hline Hardness/Shore A & $39 \pm 1$ & $41 \pm 2$ & $42 \pm 2$ & $43 \pm 1$ & $43 \pm 2$ & $44 \pm 1$ & $44 \pm 2$ \\
\hline
\end{tabular}

strength of FS-3 was enhanced by $24.5 \%$ when compared with $\mathrm{N}$-SR. It might be because that there were vinyl groups in FPLMG which contributed to the formation of concentrated crosslinking network by reacting with PHMS. More stress could be dispersed into the crosslinking network. Moreover, as discussed in Fig. 6, the molecular weight of FPLMG increased with more content of FAS. Therefore, stress would be dispersed into the concentrated crosslinking with higher molecular weight, which was favorable to the improvement of mechanical properties of ALSR.

\subsection{Effect of FPLMG on tracking resistance of ALSR}

The effect of FPLMG with different FAS content on the tracking resistance of ALSR is showed in Fig. 9. As shown in Fig. 9, the tracking resistance of N-SR was poor, and five parallel specimens failed within $1 \mathrm{~h}$. When the FAS content increased, the tracking resistance property of ALSR with FPLMG, such as FS-0, FS-1 and FS-2, was effectively enhanced, where two, three, four out of five specimens was through $6 \mathrm{~h}$ IP test. ALSR with FPLMG3, FS-3 sample, successfully passed 6 h IP test. However, ALSR samples, such as FS-4 and FS-5, did not pass $6 \mathrm{~h}$ IP test when FAS content was too high in FPLMG.

\subsection{Suppression mechanism of FPLMG on the tracking resistance of ALSR}

In the long-term operation of silicone rubber in high voltage transmission areas, the loss of hydrophobicity of silicone rubber led to the massive deposition of contaminants. The leakage current on the surface of silicone rubber dramatically increased under the applied electric field, and then arc discharge was formed. The thermal degradation of silicone rubber was caused by the heat concentration owing to the repeated discharge. Consequently, silicone rubber happened to

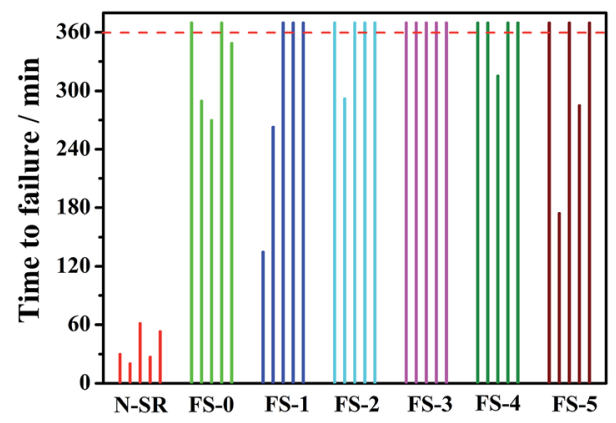

Fig. 9 Effect of FPLMG with different FAS content on the tracking resistance of ALSR. electrical tracking. As can be seen, the tracking resistance property of silicone rubber had connections with its hydrophobicity and thermal stability. Therefore, to clarify the suppression mechanism of FPLMG on the tracking resistance of ALSR, hydrophobicity and thermal stability of ALSR samples were analyzed as follows.

3.4.1 Effect of FPLMG on the hydrophobicity of ALSR. The effect of FPLMG with different FAS content on the contact angle of ALSR is showed in Fig. 10. As shown in Fig. 10, the contact angle of N-SR was $108^{\circ}$. While after adding FPLMG0, the contact angle of FS-0 decreased to $105^{\circ}$, of which the reason might be that the surface polarity of ALSR increased owing to the existence of hydroxy groups in FPLMG0. The contact angle of ALSR with FPLMG increased with more content of FAS. The contact angles of FS-1, FS-2, FS-3, FS-4 and FS-5 were $109^{\circ}, 114^{\circ}, 121^{\circ}$, $125^{\circ}$ and $126^{\circ}$, respectively, which was demonstrated the hydrophobicity of ALSR could be enhanced by the increase of FAS content in FPLMG.

3.4.2 Effect of FPLMG on the thermal stability of ALSR. Fig. 11 presents TG curves of ALSR with the addition of FPLMG with different FAS content. It was found that there were three degradation stages for N-SR in air atmosphere. The first stage from $339{ }^{\circ} \mathrm{C}$ to $419{ }^{\circ} \mathrm{C}$ was caused by the oxidation of side methyl groups and the thermal loss of impurities with low molecular weight. The second stage with large weight loss from $424{ }^{\circ} \mathrm{C}$ to $520{ }^{\circ} \mathrm{C}$ was ascribed to the oxidation of side methyl groups and the thermal decomposition of backbone. The third stage starting from $525{ }^{\circ} \mathrm{C}$ resulted from the bond scission of side methyl groups and further thermal degradation of $\mathrm{Si}-\mathrm{O}-\mathrm{Si}$ backbone. ${ }^{14}$ Besides, the temperature of $5 \%$ weight loss $\left(T_{5}\right)$ of $\mathrm{N}$-SR was $395{ }^{\circ} \mathrm{C}$, and the residues at $800{ }^{\circ} \mathrm{C}$ was $47.7 \mathrm{wt} \%$. The thermal degradation behavior of ALSR with FPLMG was similar to that of N-SR, and the thermal stability of ALSR was markedly

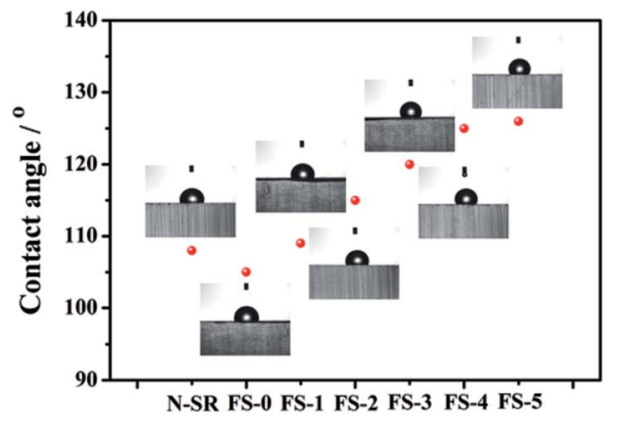

Fig. 10 The effect of FPLMG with different FAS content on the contact angle of ALSR. 


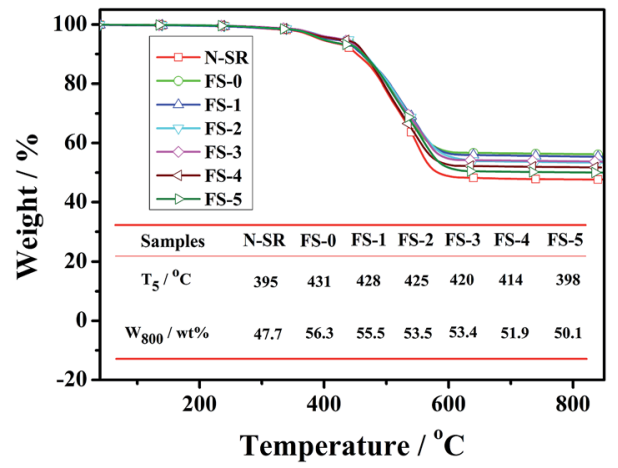

Fig. 11 TG curves of ALSR with the addition of FPLMG with different FAS content (air, $20 \mathrm{~K} \mathrm{~min}^{-1}$ ).

enhanced by FPLMG. However, the increasing amplitude of thermal stability, such as $T_{5}$ and $W_{800}$, of ALSR decreased with more FAS content in FPLMG when compared with FS-0. It might be because as shown in Fig. 8, the thermal stability of FPLMG was lowered with more addition of FAS. Therefore, the thermal stability of ALSR samples decreased when FAS content in FPLMG increased.

To further investigate the effect of FPLMG with different FAS content on the thermal stability of ALSR, ALSR samples were treated with muffle furnace at $800{ }^{\circ} \mathrm{C}$ for $10 \mathrm{~min}$. The residue and surface topography of each sample were studied. As shown in Fig. 12, the residue of $\mathrm{N}$-SR after treated at $800{ }^{\circ} \mathrm{C}$ for $10 \mathrm{~min}$ was so brittle as to be easily cracked, and the inner and external surfaces of residues turned white. After adding FPLMG, the residual content of ALSR apparently increased and, moreover, the residues, of which the inside was charred into black, were hard and compact. The reason was that a densely glassy layer on the surface of ALSR was formed by FPLMG at high temperature, which improved the ablative resistance and surface barrier effect of ALSR. Therefore, the inner of ALSR with absence of oxygen was charred into black. Fig. 12 also presented that the residual content of ALSR at $800{ }^{\circ} \mathrm{C}$ decreased with the increase of FAS content in FPLMG. The residues of ALSR, such as FS-4 and FS-5, were cracked when the FAS content was too high. It could be explained that as shown in Fig. 8, the thermal stability of FPLMG decreased with more content of FAS, which resulted in the destruction of glassy layer formed by FPLMG. Therefore,

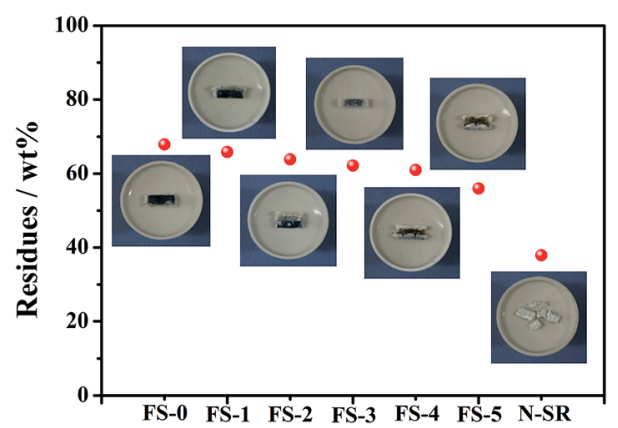

Fig. 12 Effect of FPLMG with different FAS content on the heat resistance of ALSR (air, $800^{\circ} \mathrm{C}, 10 \mathrm{~min}$ ). the residues of ALSR with FPLMG were easily cracked when FAS content was too high.

3.4.3 Analysis of pyrolysis products of ALSR with FPLMG. To further study the mechanism of FPLMG with different FAS content on the enhancement of thermal stability of ALSR, TGFTIR test was adopted to analyze the pyrolysis products of ALSR with FPLMG during its thermal decomposition. FTIR spectra of total volatile gases analyzed from 3D spectra of TGFTIR during the thermal decomposition of ALSR samples were presented in Fig. 13. The thermal decomposition of silicone rubber mainly consisted of the oxidation and bond scission of side methyl groups and thermal degradation of backbone. ${ }^{14}$ The main pyrolysis products of N-SR under air atmosphere were water $\left(3400-3700 \mathrm{~cm}^{-1}\right)$ formed by the condensation of hydroxy and oxidative degradation of side methyl groups, methane $\left(3017 \mathrm{~cm}^{-1}\right)$ produced by the bond scission of side methyl groups, $\mathrm{CO}_{2}\left(2359 \mathrm{~cm}^{-1}\right.$ and $\left.2314 \mathrm{~cm}^{-1}\right)$ and CO $\left(2179 \mathrm{~cm}^{-1}\right.$ and $\left.2114 \mathrm{~cm}^{-1}\right)$ generated from the oxidative degradation of side methyl groups, carbonyl compound (1745 $\mathrm{cm}^{-1}$ ) caused by the oxidative breakage of side methyl groups, and cyclic oligomers $\left(1074 \mathrm{~cm}^{-1}\right.$ and $\left.849 \mathrm{~cm}^{-1}\right)$ produced by thermal degradation of backbone. The kinds of pyrolysis products of ALSR with FPLMG were similar to those of $\mathrm{N}-\mathrm{SR}$, but there existed the difference in relative peak intensity.

Fig. 14 presents the FTIR absorbance vs. temperature curves of pyrolysis products of ALSR in air atmosphere. As for N-SR, the main pyrolysis products were carbonyl compound and $\mathrm{CO}_{2}$ below $400{ }^{\circ} \mathrm{C}$, indicating that there were mainly the oxidative breakage and degradation of side methyl groups for N-SR below $400{ }^{\circ} \mathrm{C}$. When temperature was elevated, N-SR primarily happened to bond scission of side methyl groups and thermal degradation of backbone, which resulted in the formation of large amount of methane and cyclic oligomers. The relative intensities of $\mathrm{CH}_{4}, \mathrm{CO}_{2}$ and cyclic oligomers of ALSR with FPLMG were lower than those of N-SR, while the intensity of carbonyl compound was higher than that of N-SR except for FS0 . Moreover, the relative intensities of $\mathrm{CO}_{2}$, carbonyl compound and cyclic oligomers increased with more FAS content in FPLMG, while the relative intensity of $\mathrm{CH}_{4}$ decreased as FAS

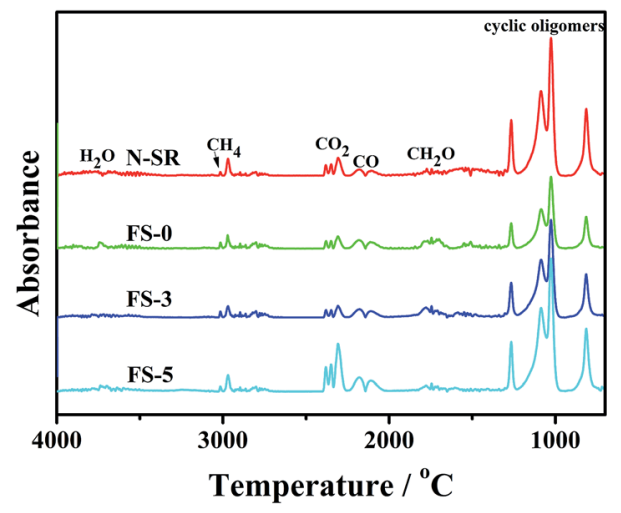

Fig. 13 FTIR spectra of total volatile gases analyzed from 3D spectra of TG-FTIR during the thermal decomposition of ALSR samples (air, $20 \mathrm{~K}$ $\left.\min ^{-1}\right)$. 

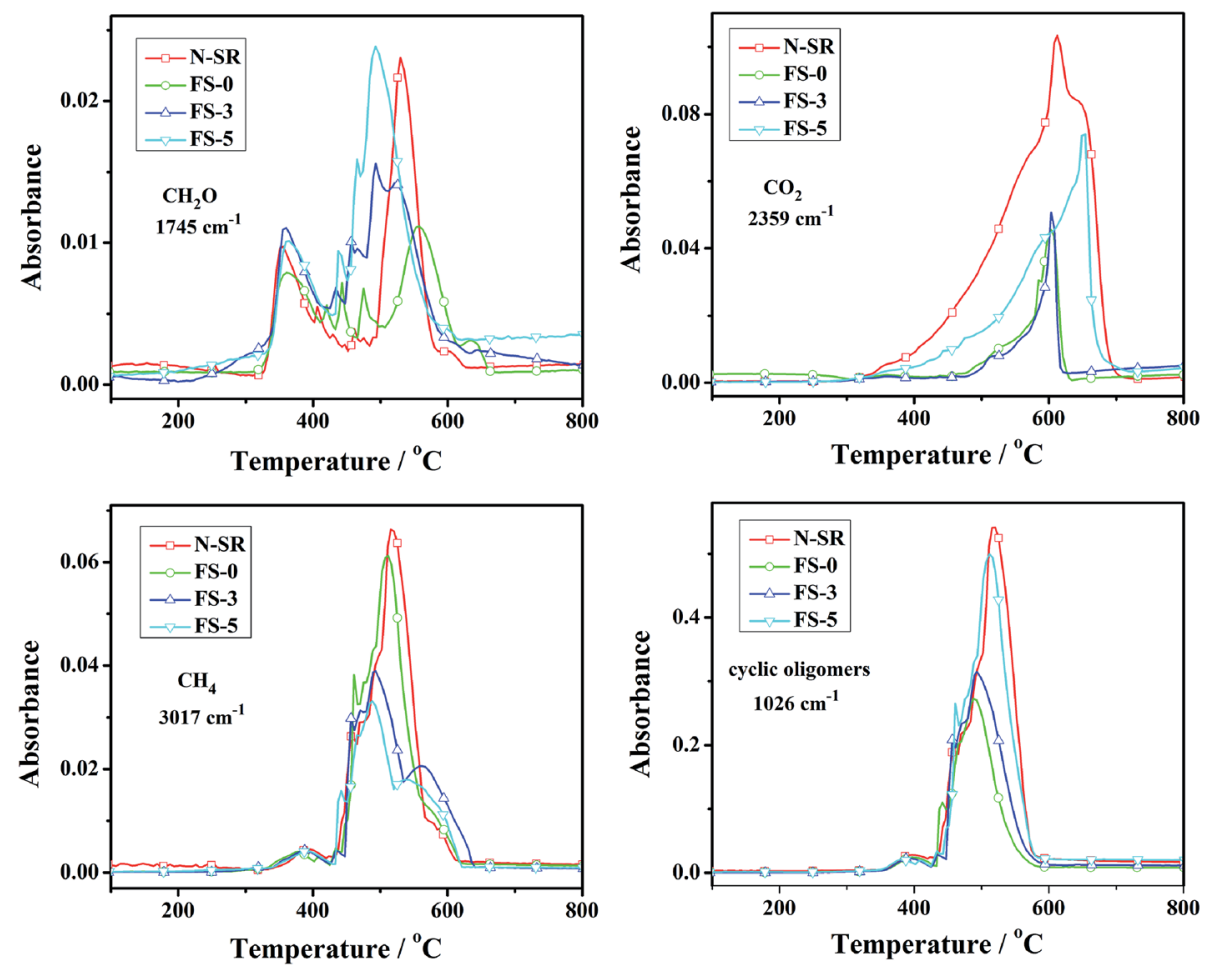

Fig. 14 The FTIR absorbance vs. temperature curves of pyrolysis products of ALSR (air, $20 \mathrm{~K} \mathrm{~min}^{-1}$ ).

content increased. It was demonstrated that, as illustrated in Fig. 12, the densely glassy layer on the surface of ALSR was formed by FPLMG with low FAS content, which hindered oxygen and heat from penetrating into the inside of matrix. Therefore, the main pyrolysis products were $\mathrm{CH}_{4}$ produced from bond scission of side methyl groups and cyclic oligomers generated from thermal degradation of backbone. While thermal stability of FPLMG decreased with high FAS content, and the glassy layer on the surface of ALSR was easily cracked. Therefore, there were primarily carbonyl compound and $\mathrm{CO}_{2}$ caused by oxidative degradation of side methyl groups and cyclic oligomers caused by thermal degradation of backbone. Overall, the thermal stability of ALSR was effectively improved by suppressing the thermal degradation of backbone.

All in all, in combination with above discussion about the effect of FPLMG on hydrophobicity and thermal stability of ALSR, it might be thought that the tracking resistance of ALSR was enhanced by means of the improvement of hydrophobicity and thermal stability of ALSR. On one hand, hydrophobicity of ALSR was improved because of the incorporation of fluorine element, diminishing the deposition of contamination on the surface of ALSR. Meanwhile, surface charge could also be suppressed by fluorine. ${ }^{24}$ On the other hand, a glassy layer on the surface of ALSR was formed by FPLMG with appropriate FAS content at high temperature generated from arc discharge. It could hinder heat and flammable gas from transmitting into the inside of ALSR, and the thermal stability of ALSR was effectively improved. Therefore, the tracking resistance of ALSR was enhanced by FPLMG with proper FAS content.

\section{Conclusions}

In this work, fluorine-containing polysiloxane low-melting glass (FPLMG) was prepared by hydrolysis-condensation of tridecafluorooctyltriethoxysilane (FAS), vinyltriethoxysilane (ViTES) and phenyltriethoxysilane (PhTES) via one-step hydrochloric acid catalyzed sol-gel method. FPLMG had amorphous ladder-like structure, and was in glassy state at room temperature. The molecular weight and glass transition temperature of FPLMG increased with more addition of FAS. And the tracking resistance and mechanical properties of ALSR were effectively enhanced by FPLMG. ALSR/FPLMG specimens successfully passed $6 \mathrm{~h}$ IP test when FAS content was $5.7 \mathrm{~mol} \%$. The hydrophobicity of ALSR with FPLMG was also improved with more content of FAS. TG, TG-FTIR and high temperature heat treatment demonstrated that FPLMG could significantly improve the thermal stability of ALSR because of the enhancement of ablative resistance and surface barrier effect of ALSR by forming a dense and compact glassy layer. Therefore, the tracking resistance of ALSR with FPLMG was enhanced by means of the improvement of hydrophobicity and thermal stability of ALSR.

\section{Acknowledgements}

This work was supported by the National Natural Science Foundation of China (No. 51573052 and No. 51403067), the Guangzhou Science and Technology Plan Project (201604010056) and the Pearl River S\&T Nova Program of Guangzhou (201710010062). 


\section{Notes and references}

1 L. Meyer, S. Jayaram and E. A. Cherney, IEEE Trans. Dielectr. Electr. Insul., 2004, 11, 620-630.

2 S. H. Kim, E. A. Cherney, R. Hackam and K. G. Rutherford, IEEE Trans. Dielectr. Electr. Insul., 1994, 1, 106-123.

3 R. A. Ghunem, S. H. Jayaram and E. A. Cherney, IEEE Elect. Insul. Mag., 2015, 31, 12-21.

4 W. J. Chen, X. R. Zeng, X. J. Lai, H. Q. Li, W. Z. Fang and F. Hou, ACS. Appl. Mater. Interfaces, 2016, 8, 21039-21045.

5 Y. H. Shi, X. X. Gao, D. Zhang, Y. F. Liu and G. S. Huang, RSC Adv., 2014, 4, 41453-41460.

6 D. Ghosh, S. Bhandari, T. K. Chaki and D. Khastqir, RSC Adv., 2015, 5, 57608-57618.

7 S. A. Seyedmehdi, H. Zhang and J. Zhu, Appl. Surf. Sci., 2012, 258, 2972-2976.

8 K. Siderakis, D. Agoris and S. M. Gubanski, IEEE Trans. Power Del., 2008, 23, 2270-2277.

9 X. D. Liang, S. W. Wang, J. Fan and Z. C. Guan, IEEE Trans. Dielectr. Electr. Insul., 1999, 6, 586-594.

10 L. E. Schmidt, X. Kornmann, A. Krivda and H. Hillborg, IEEE Trans. Dielectr. Electr. Insul., 2010, 17, 533-540.

11 B. Venkatesulu and M. J. Thomas, IEEE Trans. Dielectr. Electr. Insul., 2010, 17, 615-624.

12 S. Ansorge, F. Schmuck and K. O. Papailiou, IEEE Trans. Dielectr. Electr. Insul., 2015, 22, 979-989.

13 R. A. Ghunem, S. H. Jayaram and E. A. Cherney, IEEE Trans. Dielectr. Electr. Insul., 2015, 22, 14-20.

14 W. Z. Fang, X. J. Lai, H. Q. Li, W. J. Chen, X. R. Zeng, L. P. Zhang and S. G. Yang, Polym. Test., 2014, 37, 19-27.

15 W. J. Chen, X. R. Zeng, X. J. Lai, H. Q. Li, W. Z. Fang and T. Liu, Thermochim. Acta, 2016, 632, 1-9.

16 Z. L. An, Q. Q. Yin, H. H. Xiao, D. L. Xie, F. H. Zheng, Q. Q. Lei and Y. W. Zhang, IEEE Trans. Dielectr. Electr. Insul., 2015, 22, 1124-1133.

17 Y. Q. Liu, Z. L. An, Q. Q. Yin, F. H. Zheng, Q. Q. Lei and Y. W. Zhang, IEEE Trans. Dielectr. Electr. Insul., 2013, 20, 1859-1868.
18 B. X. Du, J. Li, H. Du and Y. Yin, IEEE Trans. Dielectr. Electr. Insul., 2014, 21, 1817-1823.

19 B. X. Du, J. Li and W. Du, IEEE Trans. Dielectr. Electr. Insul., 2013, 20, 947-995.

20 Y. J. Jiang, L. Li, J. P. Liu, R. Wang, H. S. Wang, Q. Tian and X. Y. Li, J. Fluorine Chem., 2016, 183, 82-91.

21 S. H. Gao, M. K. Lei, Y. Liu and L. S. Wen, Appl. Surf. Sci., 2009, 255, 6017-6023.

22 S. R. Coulson, I. S. Woodward, S. A. Brewer, C. Willis and J. P. S. Badyal, Chem. Mater., 2000, 12, 2031-2038.

23 D. X. Han, L. Q. Zhu, Y. C. Chen, W. P. Li, X. M. Wang and L. Ning, $R S C A d v$., 2015, 5, 22847-22855.

24 B. X. Du, Z. L. Li and J. Li, IEEE Trans. Dielectr. Electr. Insul., 2014, 21, 2338-2342.

25 H. Masai, M. Takahashi, Y. Tokuda and T. Yoko, J. Mater. Res., 2005, 20, 1234-1241.

26 D. Yu, M. Kleemeier, G. M. Wu, B. Schartel, W. Q. Liu and A. Hartwig, Polymer, 2011, 52, 2120-2131.

27 D. Yu, M. Kleemeier, G. M. Wu, B. Schartel, W. Q. Liu and A. Hartwig, Polym. Degrad. Stab., 2011, 96, 1616-1624.

28 Z. L. An, H. H. Xiao, F. L. Liu, F. H. Zheng, Q. Q. Lei and Y. W. Zhang, IEEE Trans. Dielectr. Electr. Insul., 2016, 23, 2278-2287.

29 W. Z. Fang, X. R. Zeng, X. J. Lai, H. Q. Li, W. J. Chen and Y. J. Zhang, Thermochim. Acta, 2015, 605, 28-36.

30 M. Unno, A. Suto and T. Matsumoto, Russ. Chem. Rev., 2013, 82, 289-302.

31 Z. X. Zhang, J. Hao, P. Xie, X. Zhang, C. C. Han and R. Zhang, Chem. Mater., 2008, 20, 1322-1330.

32 S. S. Choi, H. S. Lee, S. S. Hwang, D. H. Choi and K. Y. Baek, J. Mater. Chem., 2011, 20, 9852-9854.

33 C. Q. Liu, H. T. Zhao, P. Xie and R. B. Zhang, Polym. Chem., 1999, 38, 2702-2710.

34 C. Liu, Y. L. Liu, Z. R. Shen, S. P. Xie, R. B. Zhang, Z. J. Yang and F. L. Bai, Macromol. Chem. Phys., 2001, 202, 1581-1585.

35 A. Kowalewska, M. Nowacka and T. Makowski, eXPRESS Polym. Lett., 2015, 9, 984-1000. 